Portland State University

PDXScholar

$1-1-2010$

\title{
A Comparison of Single Word Identification, Connected Speech Samples, and Imitated Sentence Tasks for Assessment of Children with a SSD
}

Emily Katherine Snyder

Portland State University

Follow this and additional works at: https://pdxscholar.library.pdx.edu/open_access_etds Let us know how access to this document benefits you.

\section{Recommended Citation}

Snyder, Emily Katherine, "A Comparison of Single Word Identification, Connected Speech Samples, and Imitated Sentence Tasks for Assessment of Children with a SSD" (2010). Dissertations and Theses. Paper 362.

https://doi.org/10.15760/etd.362

This Thesis is brought to you for free and open access. It has been accepted for inclusion in Dissertations and Theses by an authorized administrator of PDXScholar. Please contact us if we can make this document more accessible: pdxscholar@pdx.edu. 
A Comparison of Single Word Identification, Connected Speech Samples, and Imitated Sentence Tasks for Assessment of Children with a SSD

by

Emily Katherine Snyder

A thesis submitted in partial fulfillment of the requirements for the degree of

\author{
Master of Science \\ in \\ Speech and Hearing Sciences
}

Thesis Committee:

Christina Gildersleeve-Neumann, Chair

Shelly Chabon

Mary Gordon-Brannan

Portland State University

2010 


\begin{abstract}
Speech-language pathologists are constantly trying to use the most efficient and effective assessments to obtain information about the phonetic inventory, speech sound errors, and phonological error patterns of children who are suspected of having a speech sound disorder. These assessments may involve a standardized measure of single words and/or sentences and a non standardized measure, such as a spontaneous speech sample. While research has shown both of these types of assessments to give clinicians information about a child's speech production abilities, the use of delayed imitation tasks, either words or sentences, has not been a widely studied topic and has produced conflicting results when researched.
\end{abstract}

The purpose of the present study was to examine speech sound production abilities in children with a speech sound disorder in a single-word task, an imitated sentence task, and spontaneous speech sample to compare their results of speech sound errors, phonological error patterns, and time administration. The study used the Phonological and Articulatory Bilingual Assessment - English version (PABA-E, Gildersleeve-Neumann , 2008), a formal assessment for identifying children who may have a speech sound disorder.

Three male children, between the ages of 4;0 and 5;4 (years;months), participated in this study. All participants were being treated by a speechlanguage pathologist for a diagnosed speech sound disorder and had hearing 
within normal limits.

The results of the study showed that the majority of participants produced the highest number of speech sounds targeted within the imitated sentence task. Participants attempted and produced the least amount of speech sounds on their spontaneous speech sample. The assessment with the highest percentage of accurately produced consonants was the imitated sentence task. The majority of participants produced a higher number of error patterns in their single-word and imitated sentence task. In terms of efficiency and effectiveness, the imitated sentence task took the least amount of time to administer and transcribe. 


\section{Table of Contents}

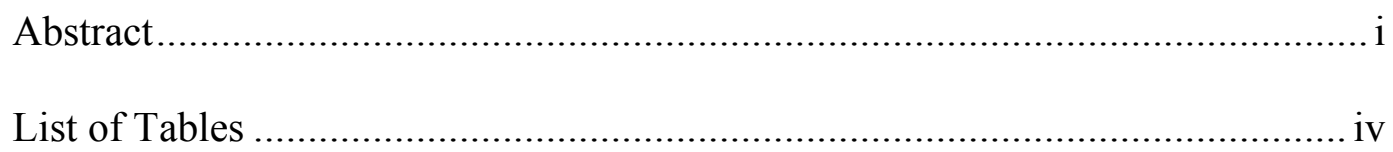

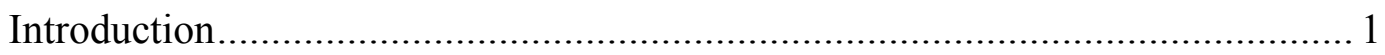

Review of the Literature ....................................................................... 3

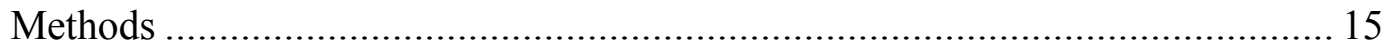

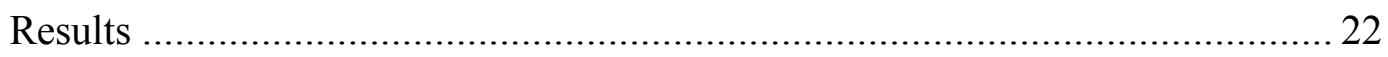

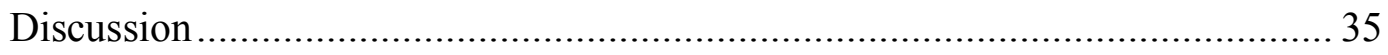

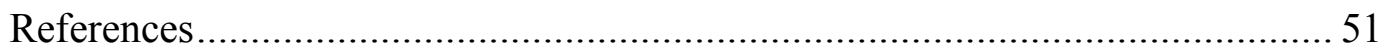

Appendix A: Parent Questionnaire of Child's Speech Development ................. 56

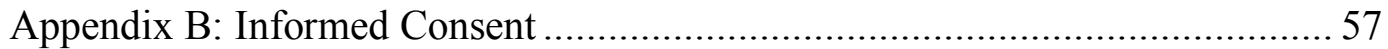

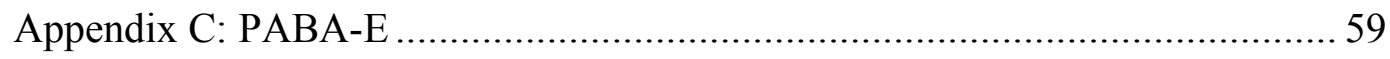




\section{List of Tables}

\section{Table 1}

Daniel's Speech Sound Inventory of Consonants and Vowels Produced, Not Produced, and Not Attempted for Assessments.

\section{Table 2}

Micah's Speech Sound Inventory of Consonants and Vowels Produced,

Not Produced, and Not Attempted for Assessments.

\section{Table 3}

Eli's Speech Sound Inventory of Consonants and Vowels Produced,

Not Produced, and Not Attempted for Assessments.

\section{Table 4}

Percent Consonants Correct for SWT, IST \& SSS

\section{Table 5}

Daniel's Percent of Consonants Correct by Word Position for

SWT, IST, \& SSS.

\section{Table 6}

Micah's Percent of Consonants Correct by Word Position for

SWT, IST, \& SSS.

\section{Table 7}

Eli's Percent of Consonants Correct by Word Position for SWT, IST, \& SSS .... 30

\section{Table 8}

Daniel's Error Patterns by Percent Occurrence for SWT, IST, \& SSS

Table 9

Micah's Error Patterns by Percent Occurrence for SWT, IST, \& SSS

Table 10

Eli's Error Patterns by Percent Occurrence for SWT, IST, \& SSS.

\section{Table 11}

Participant Time Elicitation and Transcription Time of 


\section{Introduction}

An assessment of a child with a suspected speech sound disorder (SSD) contains many elements. Speech-language pathologists (SLPs) can conduct their assessments in different fashions, but almost all assessments include an oral-mechanism exam, testing of the child's speech and hearing, and a parent/caregiver interview to obtain background information about their child's speech and language development and birth and medical history (Bleile, 2002; Hodson, Scherz, \& Strattman, 2002; Hoffman \& Norris, 2002; Khan, 2002; Miccio, 2002; Tyler \& Tolbert, 2002). It is important to include all these

pieces in a speech assessment because they will lead to thorough results. While keeping this in mind, clinicians are also limited to the amount of time available for assessments, so they need to complete them in a timely manner.

When children are first suspected of having a communication disorder, they are often referred to an SLP, who will complete a thorough assessment to determine if the suspicion is valid. To determine if a child has a communication disorder, an SLP must use assessment time wisely, because in most cases, time is limited when completing an assessment. Each of the components of an assessment can be critical to obtaining the information needed to identify a communication disorder and develop treatment goals for the child.

If the communication disorder concerns are related to speech, the objective of a SLP's assessment will be to determine whether the child has an SSD. Speech can refer to both articulation and phonology. Articulation includes the processes involved in planning and executing the sequences and gestures that create speech, while phonology 
refers to the organization of phonemes in a language system and systemic patterns within speech (Fey, 1992). "Speech" and "speech sounds" will be used to describe both articulation and phonology because of the difficulty in determining if one or the other or both are the cause of a child's misarticulations. The American Speech-Language-Hearing Association (ASHA) (1997-2009) describes the existence of an SSD as when children make errors in their speech beyond the age at which they are expected to produce the sounds correctly. The SSD can be characterized by an articulation disorder, whereby children exhibit difficulty with the production of a speech sound(s), and/or a phonological disorder, which is when children produce a pattern of speech sound errors resulting from an underdeveloped phonological representation of the phonemes of their language. If a child is determined to have an SSD, the assessment may lead to a recommendation for treatment and possible goals to be met in treatment (Bleile, 2002; Hodson et al., 2002; Khan, 2002; Tyler \& Tolbert, 2002).

Completing speech testing is an important piece of the assessment because it will give some of the most valuable information regarding the child's speech sound inventory and speech error patterns. Speech testing is the heart of the assessment since identifying the speech sound errors children are making will help the clinician determine if a child does have a SSD (Miccio, 2002). The SLP should assess a variety of speech sounds in initial, medial and final word positions. This information can help guide the child's treatment goals in terms of what to target next (Miccio, 2002; Tyler \& Tolbert, 2002). Since time is limited, the SLP needs to conduct an efficient and effective assessment. 


\section{Review of the Literature}

\section{Standardized and Non Standardized Measures}

To fully understand a child's speech sound system, both standardized and non standardized measures should be used during the assessment. Standardized measures are norm-referenced, meaning scores obtained from the test show how that child's speech or language is developing as compared to same-aged peers. These measures can usually be administered in a timely manner and they provide specificity and sensitivity measures. Many standardized measures exist to assess speech. Some commonly used measures are the Goldman Fristoe Test of Articulation-2 (GFTA-2, Goldman \& Fristoe, 2000), the Hodson Assessment of Phonological Patterns - 3 (HAPP-3, Hodson, 2004), and the Bankson-Bernthal Test of Phonology (BBTOP, Bankson \& Bernthal, 1990). These tests are single-word identification tasks that require the child to name a given object in a picture and/or repeat a word said by the tester. In addition, some standardized tests include sentence tasks, elicited spontaneously and/or through imitation.

Non standardized measures are not norm-referenced and are used to show how a child's speech and language is developing at the assessment point. Probes, dynamic assessment, and checking stimulability of speech sounds are part of non standardized measures, but the most common form of non standardized testing is a spontaneous speech sample of at least 50 intelligible words from the child (Hodson et al., 2002; Kahn, 2002; Tyler \& Tolbert, 2002). Obtaining a speech sample allows the clinician to hear what the child's speech sounds like in everyday conversation. A speech sample can also yield information about how intelligible the child is in connected speech. This speech sample can be collected through solo or interactive play routines or talking through wordless 
books (Hodson et al., 2002; Miccio, 2002). Using wordless books can facilitate elicitation of a speech sample because children need to fill in the story with their own words.

The need for both standardized and non standardized assessment measures has arisen through research and the clinical experience of SLPs. Historically, speech testing consisted of analyzing a recorded sample of a child's connected speech. While this method was effective, the need for a more efficient and less time consuming way of testing speech paved the way for more formal assessments such as picture naming and single-word tasks (Johnson, Winney, \& Pederson, 1980). Research is now being conducted to examine the efficacy of using both standardized and non standardized assessments for testing a child's speech (Bleile, 2002; Masterson, Bernhardt, \& Hofheinz, 2005). In 2002, Bleile began an inquiry into clinicians' routines and time management of assessing children for a SSD. This led to a clinical forum where SLPs offered their perspectives of assessment techniques (Hodson et al., 2002; Hoffman \& Norris, 2002; Khan, 2002; Miccio, 2002; Tyler \& Tolbert, 2002; Tyler et al, 2002; Williams, 2002). More recently, Masterson et al. (2005) studied the use of single-word and conversational speech samples with children with speech sound disorders.

Strengths of standardized measures. Standardized measures that assess speech production have been used regularly because of their objectivity (Gordon-Brannan \& Weiss, 2007) and ability to compare the client to same age peers in terms of speech development. Many standardized measures examine a child's speech in isolated words and sentences, rather than in connected speech. These tests can be helpful because they show errors in speech that may not occur in connected speech, especially when trying to 
gain information about multiple speech sound errors, because SLPs will want to make sure all speech sounds were targeted (Andrews \& Fey, 1986).

Single word tasks can either be elicited through spontaneous naming or imitation. Using tasks that encompass both a naming and imitated task can be important because they allow children to show their linguistic abilities with and without a clinician model and with context through pictures (Hale-Haniff \& Siegel, 1981).

Efficiency is an important feature of any type of speech assessment, and standardized measures have been shown to be very efficient when given to assess for SSD. DuBois and Bernthal (1978) studied the differences between using a more formal articulation test of imitated words and two informal measures. The descriptive study had 18 participants with children between the ages of $4 ; 3$ (years;months) and 6;2. The formal test was a spontaneous picture-naming task, and the informal measures consisted of a continuous speech task and a modeled continuous speech ask, both of which looked at a child's connected speech. Differences were found with the efficiency of the various tasks. The spontaneous picture-naming task was found to be more efficient when completing testing than both of the connected speech tasks because it took less time to administer.

Wolk and Meisler (1998) compared two means of elicitation for speech assessments: a conversational speech task and a picture-naming task. The participants, 13 males, all of whom had had no prior speech treatment, were administered both types of tasks. Results showed that similar error patterns were found in both tasks for the participants. Administering a complete picture naming task may serve as a more efficient and effective way to assess a child's speech if the same information can be found in a 
continuous speech task that is more time consuming.

Masterson et al. (2005) looked at 20 children's conversational speech samples and compared them to their single-word samples. The authors used a nonlinear phonological approach for their study. All participants were administered the Computerized Articulation and Phonology Evaluation System (CAPES, Masterson \& Bernhardt, 2001) that contained single words partially adapted to match the phonological system of each individual participant. Results revealed no major differences of the participants' speech production abilities between that of the conversational speech sample and the single-word samples. Their findings suggest that using single-word samples can be an effective and faster way to evaluate a child's speech sound system than collecting and analyzing a larger speech sample.

The use of standardized assessments is beneficial because of the control the clinician has over targeted words and/or sentences. Some children who are referred for assessment are highly unintelligible and knowing the adult target of what the child is saying can be very helpful in deciphering the child's speech (Gordon-Brannan \& Weiss, 2007). When transcribing the child's speech, it is helpful to have the adult target because the clinician can compare this to the child's production and uncover speech sound errors (Andrews \& Fey, 1986).

Sometimes there is not enough time to administer an entire test so SLPs may opt to give portions of a test (Bleile, 2002). Giving a single-word test can be helpful in order to hear how the child produces each sound in the English language and in every position of a word. This allows the clinician to show parents how their child's articulation is developing and contrast the scores with same-aged peers (Tyler \& Tolbert, 2002). 
Disadvantages of this type of test is does not allow the clinician to learn more about a child's phonology, such as phonological processes, (Micco, 2002) or to hear how a child produces these sounds in typical conversation when the child is not concentrating on producing each sound in the word.

Weaknesses of standardized measures. While standardized measures create a window into a child's speech sound inventory, they do contain weaknesses that must be addressed. These measures may not reveal all of the speech sound errors made by children because connected speech places a higher demand on their articulation skills, which may result in a lowered range of articulatory competency (Johnson et al., 1980).

The reduced number of errors in isolated words when compared to connected speech samples also contributes to the limitation of standardized measures. In DuBois and Bernthal's (1978) research, the spontaneous picture naming task was shown to be efficient, but the errors made by the children performing the task were fewer than the number of errors made in the continuous speech task as well as the modeled continuous speech task. Faircloth and Faircloth (1970) examined the way the same words were produced in isolation and in connected speech of an 11-year-old male with a SSD. They found that the words produced in isolation were more intelligible than when heard in connected speech. Because of their results, Johnson et al. (1980), who conducted a comparable study to DuBois and Bernthal (1978) and Faircloth and Faircloth (1970), suggested using more formal means of testing as mere screening tools and to rely on the child's connected speech sample for a more accurate depiction of the child's speech errors.

Healy and Madison (1987) expanded on previous research findings by examining 
the differences in number and types of errors found in single-word tasks and connected speech. They analyzed the type and frequency of errors patterns in the connected speech and single-word tasks of 20 children with SSD. Their findings yielded similar results of a higher percentage of errors in connected speech than single words, and found that error migration (i.e., a change regarding the status of a speech sound error from single-word productions to connected speech; no error to an error, an error to no error, or an error to a different error) could help to predict errors from single words to connected speech. It was found that omission of sounds in single words could translate to distortions, substitutions, or even correct productions in connected speech.

Strengths of spontaneous speech samples. In contrast to standardized measures, connected speech samples measure information not found in formal assessments. Faircloth and Faircloth (1970) concluded from their study of standardized measures and connected speech that a spontaneous connected speech sample can be analyzed for a more representative picture of a child's speech sound errors because it shows the way a child moves from word to word, either with accuracy or error. They found that the child produced those same words correctly in isolation and concluded that these differences were because the words were not being manipulated by surrounding speech sounds.

Eliciting and analyzing a spontaneous connected speech sample may reveal more speech errors than standardized measures. Many researchers have noted that connected speech can reveal a greater number of speech errors (e.g., phonological error patterns) across words than in single words (DuBois \& Bernthal, 1978; Healy \& Madison, 1987; Klein, 1984; Morrison \& Shriberg, 1992). Recently, Klein and Liu-Shea (2009) conducted a study to account for the discrepancies between intelligibility of single words 
and of connected speech in children with SSD. This study used between-word simplification patterns. Single word and continuous speech samples were collected from 4 boys to analyze the between-word patterns. Results showed substitution and deletions by the 4 children, which occurred when between-word patterns were analyzed that might not have been seen or occurred if only the single-word assessment was given. This is important for SLPs to note because the pattern of errors in a child's speech may not be noticed otherwise, if between-word analyses did not take place.

Weaknesses of spontaneous speech samples. Even though clinicians can obtain speech information from speech samples, there are limitations. When trying to elicit a spontaneous speech sample, it is not always known what speech sounds might be heard from the child. The child is voluntarily producing speech rather than imitating or answering test questions and thus may avoid certain speech sounds that are too difficult to produce (DuBois \& Bernthal, 1978). The SLP may be able to probe for specific speech sounds, but this is not always possible when listening to connected speech. Unpredictability of a child's utterances can lead to problems with transcription of the speech sample. When obtaining a spontaneous speech sample, the context may be known because the clinician has set it up, but if the child is very unintelligible, the clinician may have difficulty analyzing the sample for errors if the adult target is not known (Haynes \& Stead, 1987; Paden \& Moss, 1985).

Some researchers question Morrison and Shriberg's (1992) suggestions that support the use of conversational speech samples as a sufficient valid measure of a child's speech sound errors. Ingram (1994) argued that there wasn't enough evidence to claim that standardized measures would not be a comparable method to test articulation. 
Morris, Wilcox, and Schooling (1995) suggested that spontaneous speech samples can be effective in obtaining the necessary speech sound error information, but the unpredictability of a child's conversation can hinder a speech assessment that only uses this type of measure.

The time it takes to collect and analyze a spontaneous speech sample can present a challenge during a speech assessment. Collecting the speech sample may take time because it is recommended that clinician's collect 50 intelligible utterances (Bleile, 2002) or 100 words (Gordon-Brannan \& Weiss, 2007) to obtain a representative sample of a child's connected speech. A connected speech sample of this size typically takes much longer to complete than giving and scoring a standardized measure for speech sound error information (DuBois \& Bernthal, 1978; Haynes \& Stead, 1987; Johnson et al., 1980; Masterson et al., 2005; Wolk \& Meisler, 1998).

\section{A Need for Standardized and Non Standardized Measures}

While a majority of studies have found strengths and weaknesses for standardized and non standardized speech assessment measures, an overwhelming finding has been the need for the use of both types of measures because the information from each complements the other (Andrews \& Fey, 1987; Dyson \& Robinson, 1987; GordonBrannan \& Weiss, 2007; Morris et al., 1995). The complex nature of a child's speech intelligibility may also contribute to the need for both types of measures (Morris et al., 1995).

Andrew and Fey's (1986) research examined the speech sound errors of 14 children with a speech sound disorder in a labeling task of single words and connected speech. Although differences of errors were found after analyzing both tasks, the 
similarity of errors was greater. Despite this similarity, Andrew and Fey suggested that assessing a child for a SSD should include standardized and non standardized testing because the clinician needs to have a comprehensive understanding of the child's phonological system, which could not be determined without both. From analyzing both measures, the clinician could decide how to best move forward with the child's intervention, assuming the child is found to have a SSD.

Clinicians use information gained from analyzing individual speech sound errors and phonological error patterns in both standardized and non standardized testing to develop intervention goals for their clients. To only use information from one measure to move forward with intervention would not be best practice for clinicians because, as studies have shown, there is a need for both standardized and non standardized measures (Dyson \& Robinson, 1987). Since treatment targets may reflect the speech errors found in the results of assessment, only using one source to assess a child would not fully represent a child's speech sound inventory and may result in less appropriate treatment targets.

Comparison of Speech Sound Errors Found in Speech Assessments

Research results cited above suggest speech sound errors found in single-word or sentence tasks may not necessarily be the same as the errors found in connected speech sampling. Connected speech samples, in particular spontaneous speech samples, can reveal speech sounds errors that are phonological in nature (Healy \& Madison, 1987), which can lead treatment goals into a different direction. Phonological error patterns can also show up in single-word tasks, but Klein (1984) found final consonant deletion, stopping, neutralization, and weak syllable deletion to occur more often in spontaneous 
speech samples.

Johnson et al.'s (1980) research of 35 children with a speech sound disorder suggested different errors between single-word tasks and connected speech samples. They observed error migration such that speech sound errors made at the single-word level were produced as a different error type when produced in connected speech (e.g., substitution errors found in single words were produced as omission errors in connected speech). Approximately one third of the errors identified in connected speech were produced correctly within single words.

With so many different speech sound errors being documented from various speech assessments, clinicians must use good judgment when developing treatment goals. Clinicians must take into consideration all the information obtained in the speech assessments in order to identify which speech sounds or phonological error patterns to target and at what level. A combination of standardized and non standardized measures can aid in this effort to create appropriate speech goals.

The use of an imitated sentence task within an assessment has not been a large part of past or recent research concerning speech testing. Few studies have compared and imitated sentence task with either single-word tasks or spontaneous speech samples. Research conducted by DuBois and Bernthal (1978), Faircloth and Faircloth (1970), and Smith and Ainsworth (1967) compared the use of an imitated task, either words or sentences, with connected speech and found that the majority of the participants' spontaneous productions had a higher number of speech errors than imitated productions. Contradictory results from Paynter and Bumpas (1977) and Siegel, Winitz, and Conkey (1963) showed that there was no difference between participants' spontaneous or imitated 
productions.

Purpose of the Present Study

The challenge for SLPs is the use of efficient and effective articulation assessments that will provide a complete sample of a child's speech. Given the time constraint on assessments, SLPs are continually trying to find ways to get through all the necessary assessment components in one session. Many SLPs have considerable assessment time constraints and need assessment instruments that take less time to administer. Articulation tests typically assess speech production at the word level; however, speech error patterns have been shown to differ between single-word and connected speech production. Therefore, tests should be available that assess speech production at both the word and sentence levels. Assessment time needs to contain articulation testing at the word and sentence level, sounds in various positions, not only in formal testing, but in a more naturalistic setting to hear connected speech. When these assessments are used, not only will the SLP have a more complete picture of the child's speech, but the SLP will have sufficient information to determine if treatment is warranted and to gain the information needed to establish goals to be targeted in treatment (Bleile, 2002; Hodson et al., 2002; Hoffman \& Norris, 2002; Khan, 2002; Miccio, 2002; Tyler \& Tolbert, 2002). If clinicians do not obtain a representative sample of children's speech sound inventory, their goals in treatment may not address all of their needs (Miccio, 2002). As a consequence, clinicians might administer some of the child's treatment and realize that they have missed something.

To better understand if there are means to achieve efficient and thorough assessments of connected speech, the present study will examined speech sound 
productions in children with a speech sound disorder in single-word tasks, imitated sentence tasks, and spontaneous speech to compare the results of speech sound errors, phonological error patterns, and time of administration.

This study utilized a single-word and imitated sentence task, the Phonological and Articulatory Bilingual Assessment - English (PABA-E, Gildersleeve-Neumann, 2008). The PABA-E is a formal assessment for identifying children who may have a SSD, and it includes a single-word task and an imitated-sentence task. This assessment instrument is being validated with monolingual English and bilingual Spanish-English speakers. The research question for this study was: will performance on the PABA-E single-word and imitated-sentence tasks produce similar results regarding speech production ability when compared to a connected speech sample of a child with a speech sound disorder? Administration time was also examined to look at the efficiency of each assessment. 


\section{Methods}

\section{Participants}

Three male children with speech sound disorders participated in this study. Two children were 4;0 ( 4 years, 0 months) and one child was $5 ; 4$ at the time of participation. More than 30 preschools in the Portland area, the educational school district, and the Portland State University's (PSU) Speech-Language and Hearing (SPHR) clinic were contacted for potential participants. The parents of each of the potential participants were notified by phone and email to inform them of the current study and to request permission for their child to participate in the study. All parents who agreed to participate in the study were sent a questionnaire (Appendix A) through email, which was completed and sent back to the researcher. The questionnaire was used to gain more information about each participant's speech development. The researcher also used the questionnaire to determine eligibility of participation for each child. Parents of children who qualified for participation in the study were given a consent form (Appendix B) to sign, which gave their child permission to participate in the study.

The original intent was to include 12 children between the ages of $3 ; 0$ and 5;0 who were currently receiving intervention for a SSD from an SLP. However, only five parents responded to the request; of those, two of the children did not match the researcher's need for participants because they had a moderate to severe hearing loss or language impairment.

The three children who participated in this study were monolingual English speakers and had passed a hearing screening within the last 6 months. One parent reported their son as having a mild hearing loss, but was not concerned about his hearing 
because he had pressure equalization (PE) tubes in his ears. The same participant was also seeing a speech pathologist for a mild language disorder.

\section{Materials}

The PABA-E was administered and a spontaneous speech sample was obtained. The PABA-E has two components: a single-word task, which has 135 words, and an imitated sentence task that has 18 sentences including many of the words in the singleword task. The word and sentence lists are included as Appendix C.

The researcher used wordless picture books by Mercer Mayer to elicit a speech sample for the participants. The wordless books were used to provide a uniform way of examining the speech samples, rather than using different materials for each participant. Children had their choice of three Mercer Mayer books, A Boy, a Dog, and a Frog (Mayer, 1969), Frog Goes to Dinner (Mayer, 1974), and One Frog Too Many (Mayer, 1975).

\section{Procedures}

The testing took place in the location most convenient to the parents. For participants Daniel (participants' names have been changed for confidentiality) and Micah, who was a client in PSU's SPHR clinic, testing took place in their respective homes. For Eli, who was also a client in PSU's clinic, testing took place in an observable PSU SPHR clinic room with a one-way mirror. Parents and siblings had the option to stay in the room while their child/sister/brother was being tested, but were encouraged to observe, rather than be in the room, in order to achieve the least amount of distraction. All the parents and siblings, expect for Micah's mother, opted to stay out of the room while the assessments took place. Micah's mother stayed in the room because she 
wanted to keep her son focused. Daniel and Eli's testing took place on the floor at the request of the participants. Micah's testing took place at his dining room table. The examiner was seated across from the participant for all testing situations. Conditions for testing were controlled to the extent of placing a "Quiet - Testing in Progress" sign in front of the clinic room door.

Each assessment was videotaped using a Sony Handycam video camera and audiotaped using a Sony ICD-P620 recorder for transcription purposes and to record the length of time each task took. All assessments were conducted in a single sitting. Since there were only three participants and three assessments, the order of each assessment was rotated so no one had the same order of testing.

The PABA-E single-word and imitated sentence task were administered by the graduate student researcher of the study. Each child was seated at a table or on the floor across from the examiner. For the single-word task, participants were shown a stimulus picture containing a target speech sound. The examiner asked the child to spontaneously label the picture by asking, "This is a ___?" If the child did not spontaneously label the picture, the examiner said, "This is a __. What is this?" If the child still did not answer, the examiner said, "Please say ___ and instructed the child to imitate the production.

The sentence task was administered to participants by showing each child a picture illustrating a sentence containing target sounds. The child was instructed to look at the picture, listen to the examiner say a sentence, and then repeat the same sentence. If the child did not respond or imitate more than $50 \%$ of the given sentence, the examiner repeated the sentence and had the child imitate one more time. A sentence was not 
included in the data for analysis if the child did not imitate a given sentence after three prompts or did not imitate more than $50 \%$ of the stimulus sentence. Imitated sentences containing $50 \%$ or more of original stimulus words were included for analyses and were compared to the target of the utterance produced.

For the speech sample, the clinician collected 100 words to analyze for Micah's speech sample, 50 utterances for Daniel's speech sample, and just under 50 words for Eli's speech sample since he did not complete a full sample. The clinician sat on the floor or at a table with the child and caregiver, if present, and asked the child to choose one of three Mercer Mayer books to look through. The clinician looked through each page of the book with the child and commented on funny or odd moments in the book by pointing to the scene and laughing. If the child commented on a page in the book, the clinician would acknowledge the comment and encourage more speech production by asking opened-ended questions. After the initial review of the book, the clinician asked the child to narrate the story by saying, "Tell me what is happening in the book by looking at the pictures?" As the clinician turned each page of the book, she gave adequate wait time to the child (i.e., $5-8$ seconds) to begin talking, and if the child did not speak, the clinician prompted the child to talk by asking, "What is happening here?," and pointing to the page. When the child was finished narrating the book, and only if the clinician judged that the 50 utterances or 100 words had not been obtained, the clinician engaged the child in more conversation by asking the children what they liked best about the book or about a pet they might have or have had. The exception to this was Eli, who did not complete the speech sample assessment.

All three assessments were audio and video recorded in order to account for 
administration time and for phonetic transcription. The examiner noted the length of time it took to administer the two sections of the PABA-E and to obtain a speech sample by reviewing the video and audio recordings.

Analyses

Both tasks of the PABA-E and the speech samples were recorded with a digital video camera and audio recorder so the researcher could phonetically transcribe them.

All phonetic transcription was entered into a phonetic transcription computer software program, Logical International Phonetic Program (LIPP, Oller \& Delgado, 2000) in order for both tasks and speech samples to be analyzed. A LIPP program file was used to analyze words and utterances from the participant and compare them to the intended adult target. A comparison of speech error patterns was also analyzed through LIPP. If an imitated sentence from the child varied slightly from the intended target (e.g. "She is wearing noisy shoes" becomes "He is wearing noisy shoes"), the expected target was changed to reflect the child's utterance. If an utterance from a speech sample was unintelligible, it was not included for relational analyses, but was still used to provide information for the child's phonetic inventory.

An independent analysis was performed, through LIPP, by completing a speech sound inventory for each participant. This included recording the consonants and vowels each participant produced, did not produce, and did not attempt in each of the assessments given. If a consonant or vowel was not attempted, it meant that the participant did not attempt to produce an adult target that contained that particular speech sound.

A relational analysis was completed for all the participants by considering the 
three types of data: PABA-E single-word task, imitated sentence task, and spontaneous speech sample. A comparison of phonological error patterns depended on the results of the data. The phonological error patterns analyzed were fronting, backing, final consonant deletion, stopping, cluster reduction, and liquid simplification (Shriberg \& Kwiatkowski, 1980). Percent of consonants correct (PCC; Shriberg, Austin, Lewis, McSweeny, \& Wilson, 1997) for each assessment and by word position (i.e. initial, medial, final) was calculated for each participant. This percentage was based on the number of consonants produced correctly out of the total number of consonants targeted. Although speech error patterns and PCC were calculated for Eli's speech sample, they were not included in the discussion of higher and lower percentages for each analysis because his speech sample was incomplete.

Along with the administration time for each assessment and participant, the amount of time needed for each transcription (i.e. PABA-E tasks and speech sample) was also noted.

\section{Reliability}

In order to ensure the reliability of transcription of the speech samples, a second year, PSU SPHR graduate student clinician, who had had adequate training and experience with transcription, transcribed a random sample (5\%) of the total transcription for each of the assessments. The researcher compared her transcription to that of the second transcriber. A 90\% agreement with transcription was needed to show reliability of transcription. A $99.30 \%$ agreement was reached for the reliability of transcription.

\section{Examiner Effort}

The three types of data were compared and analyzed by looking at the effort 
expended by the examiner during testing and the child's response to each of the testing environments. Effort was determined by observations recorded by the examiner, through written notes, audio and video recording of targets being produced, target words and utterances in the analysis, and the amount of time needed to collect each assessment. 


\section{Results}

Each participant was administered the single word and imitated sentence task of the PABA-E and a spontaneous speech sample was obtained from them. All participants completed the single word and imitated sentence task. No words or sentences were disregarded for transcription or analysis. A complete speech sample was obtained from Daniel (50 utterances) and Micah (100 words). Micah did not complete a speech sample. Daniel used a wordless book to complete his speech sample. Micah and Eli only narrated a portion of their chosen book and needed to be engaged in further conversation to obtain more words for their speech sample.

\section{Speech Sound Inventory}

Daniel. Daniel completed the entire single-word task, imitated sentence task, and the examiner was able to obtain a complete spontaneous speech sample from Daniel using one of the Mercer Mayer wordless books.

Single-word task. Daniel took the least amount of time to complete the task out of all the participants. Daniel needed a model for about $10 \%$ of the words because he did not respond when the examiner prompted him with, "This is a

All speech sounds were attempted in this task. Daniel produced speech sound /f/, which was not produced in any other assessment task (Table 1). The speech sound was either substituted with a /d/ or omitted in the other two tasks. Speech sounds $/ v, \theta, \delta, \mathbf{s}$,

$\left.\int, t\right\}, \lambda /$ were not produced. Daniel did not produce vowel/e/. The vowel was either omitted or reduced to schwa. 


\section{Table 1}

Daniel's Speech Sound Inventory of Consonants and Vowels Produced, Not Produced, and Not Attempted for Assessments.

\begin{tabular}{|c|c|c|c|c|c|c|c|c|c|c|c|c|}
\hline \multicolumn{4}{|c|}{ SWT } & \multicolumn{4}{|c|}{ IST } & \multicolumn{5}{|c|}{ SSS } \\
\hline $\mathrm{C}$ & $\mathrm{V}$ & CNP & VNP & $\mathrm{C}$ & $\mathrm{V}$ & CNP & VNP & $\mathrm{C}$ & $\mathrm{V}$ & CNP & VNP & CNA \\
\hline$p$ & i & $v$ & e & $p$ & i & $f$ & & $b$ & $\mathrm{i}$ & $p$ & & $t 5$ \\
\hline$b$ & I & $\theta$ & & $b$ & I & $v$ & & $\mathrm{t}$ & I & f & & d3 \\
\hline $\mathrm{t}$ & $\varepsilon$ & ð & & $t$ & $\varepsilon$ & $\theta$ & & $d$ & $\mathrm{e}$ & $v$ & & \\
\hline$d$ & æ & $\mathrm{s}$ & & $d$ & $\mathrm{e}$ & ð & & k & $\varepsilon$ & $\theta$ & & \\
\hline $\mathrm{k}$ & $a$ & $\int$ & & $\mathrm{k}$ & $æ$ & $\int$ & & $\mathrm{g}$ & $æ$ & ð & & \\
\hline $\mathrm{g}$ & $\partial$ & $t$ & & $\mathrm{~g}$ & $\mathrm{a}$ & $t 5$ & & z & $a$ & $\mathrm{~S}$ & & \\
\hline$f$ & $\Lambda$ & $\lambda$ & & $\mathrm{S}$ & $\partial$ & $\lambda$ & & h & $\partial$ & $\int$ & & \\
\hline$z$ & $a$ & & & $z$ & $\wedge$ & $r$ & & $\mathrm{~m}$ & $\wedge$ & $t 5$ & & \\
\hline $\mathrm{h}$ & $\mathrm{u}$ & & & $\mathrm{h}$ & $a$ & & & $\mathrm{n}$ & $a$ & d3 & & \\
\hline$d 3$ & U & & & $d 3$ & $\mathrm{u}$ & & & $\eta$ & $\mathrm{u}$ & 1 & & \\
\hline $\mathrm{m}$ & 0 & & & $\mathrm{~m}$ & U & & & I & U & & & \\
\hline $\mathrm{n}$ & כ & & & $\mathrm{n}$ & 0 & & & $t$ & 0 & & & \\
\hline$\eta$ & $\partial$ & & & $\eta$ & 3 & & & w & 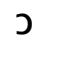 & & & \\
\hline 1 & & & & I & $\partial$ & & & $\mathrm{j}$ & $x$ & & & \\
\hline$t$ & & & & $t$ & & & & $r$ & & & & \\
\hline w & & & & $w$ & & & & & & & & \\
\hline $\mathrm{j}$ & & & & $\mathrm{j}$ & & & & & & & & \\
\hline$r$ & & & & & & & & & & & & \\
\hline
\end{tabular}

Imitated sentence task. Daniel completed the entire task. He was asked to repeat three sentences because he changed a word or two or omitted a word; he repeated the full sentence when given a second opportunity.

All speech sounds were attempted in this task. Daniel produced /s/ in this task (Table 1). He did not produce the speech sound /s/ in the other two tasks. The sound was either omitted or stopped in those assessments. Daniel did not produce speech sounds /f, 
$v, \theta, \partial \int, \mathrm{t}, \mathrm{\lambda}, \mathrm{r} / \mathrm{.}$

Spontaneous speech sample. Daniel was the only participant to use the wordless books to complete a speech sample. He produced enough utterances in his speech sample to enable the examiner to analyze a complete speech sample. After looking through the book one time, the minimum of 50 utterances needed to analyze the speech sample had almost been reached.

Daniel did not attempt to produce speech sounds $/ \mathrm{t} /$ and $/ \mathrm{d} z /$ in any of his

utterances. The consonants not produced were $/ p, f, v, \theta, \partial, s, \int, t f, d \zeta, \lambda /$. Of the speech sounds he did not produce, $/ \mathrm{p} /$ and /f/ were the only sounds that were produced in his other two tasks.

Micah. Micah completed the word and sentence task. The examiner elicited a speech sample by using the words Micah produced when describing a picture in one of the wordless book and words produced in conversation during the time of the speech sample.

Single word task. Micah completed the task and attempted all speech sounds. The only speech sounds he did not produce were $/ ð /$ and $/ /$ /, which were produced in his sentence task (Table 2). 
Table 2

Micah's Speech Sound Inventory of Consonants and Vowels Produced, Not Produced, and Not Attempted for Assessments.

\begin{tabular}{|c|c|c|c|c|c|c|c|c|c|c|c|c|}
\hline \multicolumn{4}{|c|}{ SWT } & \multicolumn{4}{|c|}{ IST } & \multicolumn{5}{|c|}{ SSS } \\
\hline $\mathrm{C}$ & $\mathrm{V}$ & CNP & VNP & $\mathrm{C}$ & $\mathrm{V}$ & CNP & VNP & $\mathrm{C}$ & $\mathrm{V}$ & CNP & VNP & CNA \\
\hline$p$ & i & ð & & $p$ & i & & & $p$ & i & d3 & & $\int$ \\
\hline$b$ & I & $\lambda$ & & $b$ & I & & & b & I & & & \\
\hline$t$ & $\mathrm{e}$ & & & $t$ & $\mathrm{e}$ & & & $t$ & e & & & \\
\hline$d$ & $\varepsilon$ & & & $d$ & $\varepsilon$ & & & $\mathrm{d}$ & $\varepsilon$ & & & \\
\hline $\mathrm{k}$ & æ & & & $\mathrm{k}$ & æ & & & $\mathrm{k}$ & æ & & & \\
\hline $\mathrm{g}$ & $a$ & & & $\mathrm{~g}$ & $a$ & & & $g$ & $\mathrm{a}$ & & & \\
\hline$f$ & $\partial$ & & & $f$ & $\partial$ & & & $f$ & ә & & & \\
\hline$v$ & $\Lambda$ & & & $v$ & $\Lambda$ & & & $\mathrm{v}$ & $\Lambda$ & & & \\
\hline$\theta$ & $a$ & & & $\theta$ & $a$ & & & $\theta$ & $a$ & & & \\
\hline$\partial$ & $\mathrm{u}$ & & & ð & $\mathrm{u}$ & & & д & $\mathrm{u}$ & & & \\
\hline $\mathrm{S}$ & U & & & $\mathrm{S}$ & U & & & $\mathrm{S}$ & U & & & \\
\hline z & 0 & & & z & 0 & & & z & 0 & & & \\
\hline $\int$ & כ & & & $\int$ & כ & & & $\int$ & כ & & & \\
\hline $\mathrm{h}$ & $\partial$ & & & $h$ & $\partial$ & & & h & $\partial$ & & & \\
\hline$t 5$ & & & & $t 5$ & & & & $t$ & & & & \\
\hline d3 & & & & ds & & & & $d_{3}$ & & & & \\
\hline $\mathrm{m}$ & & & & $\mathrm{m}$ & & & & $\mathrm{m}$ & & & & \\
\hline $\mathrm{n}$ & & & & $n$ & & & & $n$ & & & & \\
\hline$\eta$ & & & & $\eta$ & & & & $\eta$ & & & & \\
\hline I & & & & I & & & & I & & & & \\
\hline$t$ & & & & $t$ & & & & $t$ & & & & \\
\hline w & & & & w & & & & w & & & & \\
\hline $\mathrm{j}$ & & & & $\mathrm{j}$ & & & & j & & & & \\
\hline$\lambda$ & & & & $\lambda$ & & & & $d$ & & & & \\
\hline$r$ & & & & $r$ & & & & r & & & & \\
\hline
\end{tabular}

$\mathrm{SWT}=$ single-word task $\mathrm{C}=$ consonants $; \mathrm{V}=$ vowels; $\mathrm{CNP}=$ consonants not produced; $\mathrm{VNP}$ $=$ vowels not produced; $\mathrm{CNA}=$ consonants not attempted

Imitated sentence task. Micah completed the task and attempted all speech sounds. The examiner asked Micah to repeat certain sentences two or three times 
because the production was not audible or words were transposed or omitted. Micah produced all speech sounds targeted in at least one word position: initial, medial, or final.

Spontaneous speech sample. Micah reached the minimum of 100 words for his speech sample, but not by narrating one of the wordless books because he did not narrate a whole book. Instead, words produced from conversation between the examiner and child during the speech sample were used to supplement the transcription and analyses of his speech sample.

Micah produced speech sound /ð/, which was not produced in his word task. He did not attempt to produce speech sound $/ \mathrm{J} /$. He attempted, but did not produce $/ \mathrm{d} 3 /$. This speech sound was produced in his other two tasks.

Eli. Eli completed all words and sentences in the single-word and imitated sentence task. Eli did not emit a complete speech sample, but he did produce approximately 50 words, which were transcribed and used for his independent analysis.

Single word. Eli took the longest to complete the word task out of all the participants. The examiner used a game to motivate him to participate in the assessment. The examiner needed to give Eli a verbal production for him to imitate in order for him to produce a word. This was the case for over $50 \%$ of the words.

All speech sounds were attempted. Speech sounds $/ \mathrm{V} /, / \theta /$, and $/ \partial /$ were the only consonants not produced (Table 3). The sounds were either omitted or stopped. All three sounds were produced in his other two tasks. 


\section{Table 3}

Eli's Speech Sound Inventory of Consonants and Vowels Produced, Not Produced, and Not Attempted for Assessments.

\begin{tabular}{|c|c|c|c|c|c|c|c|c|c|c|c|c|}
\hline \multicolumn{4}{|c|}{ SWT } & \multicolumn{4}{|c|}{ IST } & \multicolumn{5}{|c|}{ SSS } \\
\hline C & V & CNP & VNP & C & $\mathrm{V}$ & CNP & VNP & C & V & $\begin{array}{c}\mathrm{CN} \\
\mathrm{P}\end{array}$ & $\begin{array}{c}\mathrm{VN} \\
\mathrm{P}\end{array}$ & $\begin{array}{c}\mathrm{CN} \\
\mathrm{A}\end{array}$ \\
\hline$p$ & i & V & & $\mathrm{p}$ & $\mathrm{i}$ & $r$ & & $p$ & $\mathrm{i}$ & t5 & & f \\
\hline b & I & $\theta$ & & $b$ & I & & & $b$ & I & & & $\mathrm{v}$ \\
\hline $\mathrm{t}$ & e & Ә & & $\mathrm{t}$ & e & & & $\mathrm{t}$ & e & & & $\theta$ \\
\hline d & $\varepsilon$ & & & d & $\varepsilon$ & & & d & $\varepsilon$ & & & $\int$ \\
\hline k & æ & & & $\mathrm{k}$ & $æ$ & & & k & æ & & & $d s$ \\
\hline g & $a$ & & & $\mathrm{~g}$ & $a$ & & & g & $\mathrm{a}$ & & & 1 \\
\hline f & $\partial$ & & & $f$ & $\partial$ & & & ठ & $\partial$ & & & \\
\hline $\mathrm{s}$ & $\wedge$ & & & v & $\Lambda$ & & & $\mathrm{s}$ & $\Lambda$ & & & \\
\hline z & $a$ & & & $\Theta$ & $a$ & & & z & $a$ & & & \\
\hline $\int$ & $\mathrm{u}$ & & & ठ & $\mathrm{u}$ & & & $\mathrm{h}$ & $\mathrm{u}$ & & & \\
\hline $\mathrm{h}$ & $v$ & & & $\mathrm{~s}$ & U & & & $\mathrm{m}$ & U & & & \\
\hline t5 & 0 & & & z & 0 & & & $\mathrm{n}$ & 0 & & & \\
\hline ds & J & & & $\int$ & J & & & $\eta$ & כ & & & \\
\hline $\mathrm{m}$ & $x$ & & & $\mathrm{~h}$ & $x$ & & & w & $\partial$ & & & \\
\hline$n$ & & & & to & & & & j & & & & \\
\hline $\mathrm{N}$ & & & & ds & & & & $\lambda$ & & & & \\
\hline 1 & & & & $\mathrm{~m}$ & & & & $r$ & & & & \\
\hline$t$ & & & & $\mathrm{n}$ & & & & & & & & \\
\hline w & & & & $N$ & & & & & & & & \\
\hline $\mathrm{j}$ & & & & 1 & & & & & & & & \\
\hline 1 & & & & $t$ & & & & & & & & \\
\hline$r$ & & & & w & & & & & & & & \\
\hline & & & & $\mathrm{j}$ & & & & & & & & \\
\hline & & & & $r$ & & & & & & & & \\
\hline
\end{tabular}

$\mathrm{SWT}=$ single-word task $\mathrm{C}=$ consonants $; \mathrm{V}=$ vowels $; \mathrm{CNP}=$ consonants not produced; $\mathrm{VNP}=$ vowels not produced; $\mathrm{CNA}=$ consonants not attempted

Imitated sentence task. Eli did not repeat a full sentence when the examiner asked him to imitate a sentence. He repeated one to two words at a time when the 
examiner had him imitate one to two words at a time.

All speech sounds were attempted. Eli produced every speech sound targeted in the task (Table 3), except for $/ \mathrm{A} /$. However, this speech sound was produced in his other two tasks.

Spontaneous speech sample. Eli did not attempt speech sounds /f, v, $\theta, \int, \mathrm{d}, \mathrm{l}$.

Of those speech sounds, $/ \mathrm{V} /$ and $/ \theta /$ were produced in the sentence task and $/ \mathrm{f}, \int, \mathrm{dz}, \mathrm{l} /$

were produced in both his word and sentence task. Speech sound $/ \mathrm{t} /$ was attempted, but not produced. This sound was produced in his other two tasks.

\section{Percent Consonants Correct}

PCC was compared to across each assessment for each participant. Comparing the PCC of each participant's individual assessments, as seen in Table 4, the speech sample was the assessment tool that resulted in the highest PCC for Daniel and Eli. Micah produced a higher PCC in his sentence task with $95 \%$, but his speech sample had the lowest PCC out of his assessments with 73\%. Both Daniel and Eli had the highest PCC with their speech sample with $57 \%$ and $62 \%$, respectively. The word task was the assessment with the lowest PCC for both Daniel and Eli, ranging from 52\% to 55\%.

\begin{tabular}{lcccccc}
\hline Table 4 & \multicolumn{6}{c}{ Percent Consonants Correct for SWT, IST \& SSS } \\
\hline \multirow{3}{*}{ Participant } & \multicolumn{2}{c}{ SWT } & \multicolumn{3}{c}{ IST } & \multicolumn{2}{c}{ SSS } \\
\cline { 2 - 7 } Daniel & PCC & Raw & PCC & Raw & PCC & Raw \\
Micah & SWT & Data & IST & Data & SSS & Data \\
Eli & $52 \%$ & $209 / 401$ & $54 \%$ & $150 / 277$ & $57 \%$ & $201 / 350$ \\
\hline & $54 \%$ & $314 / 401$ & $95 \%$ & $254 / 268$ & $73 \%$ & $238 / 320$ \\
& $54 \%$ & $217 / 401$ & $55 \%$ & $159 / 289$ & $62 \%$ & $68 / 109$ \\
\hline
\end{tabular}

$\mathrm{SWT}=$ single-word task; IST = imitated sentence task; SSS = spontaneous speech sample 
The PCC results for each assessment by word position were examined. These PCC scores varied for each participant and assessment. Table 5 shows PCC for the all three assessments for initial, medial, and final word position for Daniel. His speech sample yielded the highest PCC in the initial word position with 52\%. Daniel's word task contained the highest PCC in medial and final word position with $44 \%$ and $41 \%$. His lowest PCC for the initial word position was found in his word task with $46 \%$. Daniel's speech sample had the lowest PCC for medial word position with $29 \%$ and his lowest PCC for final word position was his IST with 35\%.

\begin{tabular}{lcccccc}
\hline Table 5 & \multicolumn{6}{c}{ Daniel's Percent of Consonants Correct by Word Position for SWT, IST, \& SSS } \\
\hline Assessment & Initial & Raw Data & Medial & Raw Data & Final & Raw Data \\
SWT & $46 \%$ & $60 / 132$ & $44 \%$ & $37 / 84$ & $41 \%$ & $49 / 121$ \\
IST & $50 \%$ & $59 / 119$ & $40 \%$ & $21 / 53$ & $35 \%$ & $34 / 96$ \\
SSS & $52 \%$ & $73 / 140$ & $29 \%$ & $15 / 52$ & $36 \%$ & $44 / 121$ \\
\hline \multicolumn{5}{l}{ SWT = single-word task; IST = imitated sentence task; SSS = spontaneous speech sample }
\end{tabular}

Table 6 shows the PCC for each assessment and word position for Micah. His speech sample had the highest PCC for initial, medial, and final word positions, with $26 \%, 35 \%$, and 29\%. The lowest PCC for Micah's initial and medial word position was found in his sentence task with $21 \%$ and $19 \%$. His lowest PCC for final word position was in his word task with $14 \%$.

\begin{tabular}{lcccccc}
\hline Table 6 & \multicolumn{7}{c}{ Micah's Percent of Consonants Correct by Word Position for SWT, IST, \& SSS } \\
\hline Assessment & Initial & Raw Data & Medial & Raw Data & Final & Raw Data \\
SWT & $22 \%$ & $29 / 132$ & $20 \%$ & $17 / 84$ & $14 \%$ & $17 / 121$ \\
IST & $21 \%$ & $24 / 116$ & $19 \%$ & $10 / 53$ & $18 \%$ & $17 / 94$ \\
SSS & $27 \%$ & $35 / 131$ & $35 \%$ & $9 / 26$ & $29 \%$ & $38 / 130$ \\
\hline \multicolumn{5}{l}{ SWT $=$ single-word task; IST $=$ imitated sentence task; SSS = spontaneous speech sample }
\end{tabular}

Table 7 shows PCC for all assessments and word positions for Eli. His word task had the highest PCC for initial and medial word position with 55\% and 50\%. His speech 
sample contained the highest PCC for final word position with 50\%. Eli's lowest PCC for initial and medial word position was in his speech sample with $28 \%$ and $27 \%$. The assessment that had the lowest PCC for the final word position was the sentence task with $36 \%$.

\begin{tabular}{lcccccc}
\hline Table 7 & Eli's Percent of & Consonants Correct by Word Position for SWT, IST, \& SSS \\
\hline Assessment & Initial & Raw Data & Medial & Raw Data & Final & Raw Data \\
SWT & $55 \%$ & $72 / 132$ & $50 \%$ & $42 / 84$ & $38 \%$ & $46 / 121$ \\
IST & $50 \%$ & $58 / 115$ & $48 \%$ & $25 / 52$ & $36 \%$ & $33 / 93$ \\
SSS & $28 \%$ & $16 / 58$ & $27 \%$ & $3 / 11$ & $50 \%$ & $17 / 34$ \\
\hline
\end{tabular}

SWT = single-word task; IST = imitated sentence task; SSS = spontaneous speech sample

\section{Phonological Error Patterns}

The assessment results showed all participants producing one or more phonological error patterns. The processes analyzed were stopping, final consonant deletion, cluster reduction, fronting, backing, and liquid simplification. Weak syllable deletion and assimilation were not analyzed nor addressed because none of the participants had over $1 \%$ error in those areas.

Table 8 shows the percentage of Daniel's phonological error patterns by assessment. Cluster reduction occurred most often out of all error patterns that were analyzed. Daniel's sentence task showed him reducing clusters most often at 90\%. He reduced clusters $80 \%$ of the time in his speech sample and $61 \%$ of the time in his word task. Stopping occurred frequently in all of Daniel's assessments, but the highest percentage of stopping occurred in his speech sample with $66.3 \%$. Both his word and sentence task showed occurrence of stopping at 50\%. Backing did not occur in any of Daniel's assessments. Fronting only occurred in his word task at 6\%. Final consonant deletion occurred most often in Daniel's sentence task at 50\%. His word task and speech sample showed a much lower occurrence of final consonant deletion at $28 \%$ and $24 \%$. 
Liquid simplification occurred most often in Daniel's word task at 30\%, followed by $21 \%$ in his sentence task and $11 \%$ in his speech sample.

\begin{tabular}{lcccccc}
\hline \multicolumn{6}{l}{ Table 8 Daniel's Error Patterns by Percent Occurrence for SWT, IST, \& SSS } \\
\hline Error Patterns & SWT & Raw & IST & Raw & SSS & Raw \\
Stopping & $50 \%$ & $41 / 101$ & $50 \%$ & $38 / 76$ & $66 \%$ & $57 / 86$ \\
Backing & $0 \%$ & $0 / 123$ & $0 \%$ & $0 / 86$ & $0 \%$ & $0 / 161$ \\
Fronting & $6 \%$ & $4 / 64$ & $0 \%$ & $0 / 43$ & $0 \%$ & $0 / 36$ \\
$\begin{array}{l}\text { Final } \\
\begin{array}{l}\text { Consonant } \\
\text { Deletion }\end{array}\end{array}$ & $28 \%$ & $34 / 121$ & $50 \%$ & $23 / 46$ & $24 \%$ & $29 / 121$ \\
$\begin{array}{l}\text { luster } \\
\text { Reduction }\end{array}$ & $61 \%$ & $19 / 31$ & $90 \%$ & $17 / 19$ & $80 \%$ & $12 / 24$ \\
$\begin{array}{l}\text { Liquid } \\
\text { Simplification }\end{array}$ & $30 \%$ & $15 / 50$ & $21 \%$ & $7 / 34$ & $11 \%$ & $3 / 27$ \\
\hline SWT & & & & & & \\
\hline
\end{tabular}

SWT $=$ single-word task; IST $=$ imitated sentence task; SSS = spontaneous speech sample

Table 9 shows Micah's percent occurrence of error patterns by assessment type.

The error patterns that occurred most often in Micah's speech were stopping, final consonant deletion, cluster reduction, and liquid simplification. Stopping occurred most often in his word task at $13 \%$, followed by his sentence task with $8 \%$ and his speech sample 2\%. Final consonant deletion occurred only in Micah's speech sample $9 \%$ of the time. The highest percentage of cluster reduction occurred in his speech sample at $38 \%$. He reduced clusters less frequently in his word and sentence task at $3 \%$ and $11 \%$, respectively. Liquid simplification was the error pattern that occurred the most often across all of Micah's assessments. His speech sample contained the highest percentage of liquid simplification, occurring $83 \%$ of the time, followed by his word task with $56 \%$ and then his sentence task with 38\%. Backing did occur in Micah's word task and 
speech sample, but at a very low percentage with $1 \%$ and $5 \%$. Fronting was the only phonological process analyzed that did not occur within any of his assessments.

\begin{tabular}{lc|c|c|c|c|c}
\hline \multicolumn{6}{c}{ Table 9 } & Micah's Error Patterns by Percent Occurrence for SWT, IST, \& SSS \\
\hline Error Patterns & SWT & Raw & IST & Raw & SSS & $\begin{array}{c}\text { Raw } \\
\text { Data }\end{array}$ \\
Stopping & $13 \%$ & $3 / 101$ & $8 \%$ & $38 / 76$ & $2 \%$ & $57 / 86$ \\
Backing & $1 \%$ & $1 / 123$ & $0 \%$ & $0 / 96$ & $5 \%$ & $5 / 103$ \\
Fronting & $0 \%$ & $0 / 65$ & $0 \%$ & $1 / 43$ & $0 \%$ & $0 / 26$ \\
$\begin{array}{l}\text { Final } \\
\begin{array}{l}\text { Consonant } \\
\text { Deletion }\end{array}\end{array}$ & $0 \%$ & $0 / 121$ & $0 \%$ & $0 / 94$ & $9 \%$ & $12 / 130$ \\
$\begin{array}{l}\text { Cluster } \\
\begin{array}{l}\text { Reduction } \\
\text { Liquid }\end{array}\end{array}$ & $3 \%$ & $1 / 31$ & $11 \%$ & $2 / 19$ & $38 \%$ & $9 / 24$ \\
Simplification & $56 \%$ & $28 / 50$ & $38 \%$ & $13 / 34$ & $83 \%$ & $20 / 24$ \\
\hline SWT
\end{tabular}

SWT = single-word task; IST = imitated sentence task; SSS = spontaneous speech sample

Table 10 shows the percentage of phonological error patterns produced by Eli across all of his assessments. All error patterns that were analyzed in this study were found in all of Eli's assessments. Stopping occurred frequently in his speech sample with $39 \%$, followed by his sentence task with $35 \%$ and then his word with $25 \%$. Backing occurred at a very low percentage in all of Eli's assessments. His speech percentage of backing was $5 \%$, sentence task, $2 \%$, and word task, $1 \%$. Fronting occurred most often in Eli's speech sample at $27 \%$. His word and sentence task showed a lower percentage of fronting with $19 \%$ and $12 \%$, respectively. Final consonant deletion occurred at a similar frequency across all assessments. The highest percentage of final consonant deletion occurred in Eli's speech sample at 27\%, followed by his word task at 25\% and then his sentence task at $20 \%$. Cluster reduction occurred at a very high frequency in all of Eli's assessments. He reduced his clusters $100 \%$ of the time in his word task, $79 \%$ of the time 
in his sentence task and $71 \%$ of the time in his speech sample. Liquid simplification also occurred at a similar frequency in all of Eli's assessments. His word and sentence task had an identical percentage of liquid simplification at $21 \%$; liquid simplification occurred $14 \%$ of the time in Eli's speech sample.

\begin{tabular}{|c|c|c|c|c|c|c|}
\hline Error Patterns & SWT & $\begin{array}{l}\text { Raw } \\
\text { Data }\end{array}$ & IST & $\begin{array}{l}\text { Raw } \\
\text { Data }\end{array}$ & SSS & $\begin{array}{l}\text { Raw } \\
\text { Data }\end{array}$ \\
\hline Stopping & $25 \%$ & $25 / 101$ & $35 \%$ & $26 / 76$ & $39 \%$ & $7 / 18$ \\
\hline Backing & $1 \%$ & $1 / 123$ & $2 \%$ & $2 / 95$ & $5 \%$ & $2 / 44$ \\
\hline Fronting & $14 \%$ & $9 / 65$ & $12 \%$ & $5 / 43$ & $27 \%$ & $3 / 11$ \\
\hline $\begin{array}{l}\text { Final } \\
\text { Consonant } \\
\text { Deletion }\end{array}$ & $25 \%$ & $30 / 121$ & $20 \%$ & $19 / 93$ & $27 \%$ & $9 / 34$ \\
\hline $\begin{array}{l}\text { Cluster } \\
\text { Reduction }\end{array}$ & $100 \%$ & $31 / 31$ & $79 \%$ & $15 / 19$ & $71 \%$ & $5 / 7$ \\
\hline $\begin{array}{l}\text { Liquid } \\
\text { Simplification }\end{array}$ & $20 \%$ & $10 / 50$ & $21 \%$ & $7 / 34$ & $14 \%$ & $1 / 7$ \\
\hline
\end{tabular}

SWT $=$ single-word task; IST = imitated sentence task; SSS = spontaneous speech sample

\section{Time of Elicitation}

The time it took to administer each individual assessment varied from one child to the next. Table 11 shows the amount of time it took to complete each assessment with each child. The sentence task took the least amount of time to administer for all participants, with times ranging from 3:58 (minutes:seconds) to 7:58. The single-word task took the longest amount of time to administer, ranging from 17:30 to 27:02. The speech sample took the second longest amount of time to obtain a complete speech sample, with times ranging from 5:52 to 10:05. 


\section{Table 11}

Participant Time Elicitation and Transcription Time of Speech Assessments (minutes:seconds)

\begin{tabular}{lccccc}
\hline \multirow{2}{*}{ Participant } & TE/TT & \multicolumn{1}{c}{ SWT } & IST & SSS & $\begin{array}{c}\text { Total time of } \\
\text { assessment }\end{array}$ \\
\cline { 2 - 6 } Daniel & TE & $17: 30$ & $03: 58$ & $05: 52$ & $27: 33$ \\
& TT & $59: 00$ & $40: 00$ & $63: 00$ & \\
\hline \multirow{2}{*}{ Micah } & TE & $22: 05$ & $07: 02$ & $10: 05$ & $39: 12$ \\
& TT & $55: 00$ & $35: 00$ & $58: 00$ & \\
\hline \multirow{2}{*}{ Eli } & TE & $27: 02$ & $07: 58$ & $05: 09^{*}$ & $40: 09$ \\
\hline
\end{tabular}

*Incomplete speech sample

$\mathrm{TE}=$ time elicitation; $\mathrm{TT}=$ transcription time; $\mathrm{SWT}=$ single-word task; $\mathrm{IST}=$ imitated sentence task; SSS = spontaneous speech sample

\section{Examiner Effort}

The amount of time needed to transcribe each assessment, for each participant, is shown in Table 11. Transcription time, defined here as time spent entering a single assessment into LIPP, depended on the assessment that was being entered in LIPP. The word task and speech sample took the most time to transcribe for each participant with transcription times ranging from 56 to 59 minutes for the word task and 29 to 63 minutes for the speech sample. Overall, the IST took the least amount of time to transcribe. 


\section{Discussion}

This study examined the phonetic inventory, phonological error patterns and percent accuracy for three children with speech sound disorders. These properties of speech were examined in a single-word task, an imitated sentence task, and in a spontaneous speech sample. A comparison of the results for these assessment tools is presented below.

The results of this study showed that the imitated sentence task of the PABA-E provided the most information about each child's speech sound inventory. With the exception of Eli's sentence task, all speech sounds produced in each of the participants' sentence task were not always produced in their word task or speech sample. The only speech sound not produced in Eli's sentence task, $/ \mathbf{A}$ /, was produced in his running speech.

Error patterns were also examined within each participant's assessments. Results varied among the tasks. Although a clear picture of a participant's phonetic inventory was seen from the sentence task, no single assessment consistently showed a higher percentage of phonological error patterns over another assessment. The assessments that most frequently gave a higher percentage of error patterns were the sentence task and speech sample. In contrast, the speech samples also gave the lowest percentage of error patterns when a participant's word task or sentence task showed a higher percentage of error patterns.

PCC was calculated for each assessment and also by word position in this study. Without placing too much weight on Eli's minimal speech sample, results for the 
majority of the participants showed that the PCC was higher for the sentence task and lower for the word task. PCC for the initial word position was higher for the speech sample. For medial word position, PCC was higher in the word task. Final word position was inconclusive because all participants had a different assessment with a higher PCC. This was the same situation with assessments containing the lowest percentage of PCC. Efficiency of assessments is an important aspect of administering any speech sound assessment, and refers to the timeliness of administering and analyzing an assessment. Research has found the use of standardized assessments over non standardized assessments to be more efficient due to the short amount of time needed for administration (DuBois \& Bernthal, 1978; Masterson et al., 2005; Wolk \& Meisler, 1998). This study looked at the efficiency of each assessment and found that the sentence task was the assessment task that not only took the least amount of time to administer, but also took the least amount of time to transcribe for analyses. The speech sample took the least amount of time to obtain after the sentence task, followed by the word task.

Transcription time varied for the speech sample and word task, but the speech sample most often took the longest amount of time to transcribe.

This study revealed varying results depending on the assessment administered and on the participant. This led to the consideration of strengths and weaknesses of the three assessments and also an examination to why they may have arisen. Below these strengths and weaknesses are explored more thoroughly.

\section{Imitated Sentence Task}

The sentence task was the assessment that showed the overall abilities of each participant in terms of speech sounds they could produce in connected speech, when 
given a model to imitate. Results of this task differed by child. In the sentence task, Micah produced all of the targeted sounds in at least one word position, but more importantly, he produced speech sounds that were not recorded in either his word task or speech sample. Daniel's sentence task also showed him producing more speech sounds that were not present in his other two assessments. Eli's sentence task results differed from the other two participants because he did produce a speech sound in both his word task and speech sample that he did not produce in his sentence task, / $\mathrm{\lambda} /$. In spite of this discrepancy, the results of the sentence task are still a solid representation of what Eli could produce in connected speech.

Other strengths of the sentence task included the short time needed to administer the test compared to the other assessments, a short length of time needed to transcribe the sentences, and the ability of the assessment to obtain a small sample of a child's connected speech. The sentence task may not be the most naturalistic way to obtain a sample of a child's connected speech, but the results of this study showed the majority of participants producing a larger variety of speech sounds in the sentence task than in the speech sample.

A weakness of the sentence task was the challenge the assessments poses if a participant is seemingly not able to imitate an entire sentence. This would conceivably increase the amount time needed to administer the test, which was the case for Eli, a child with a language impairment. This impairment may have prevented him from processing and imitating more than one or two words at a time, which increased the time elicitation. Daniel, who had typical language skills, quickly imitated full sentences; therefore, his time elicitation was short. Micah also did not have a language impairment, but the time 
needed to administer the assessment was similar to Eli's because he did not want to repeat the sentences.

\section{Spontaneous Speech Sample}

The spontaneous speech sample was the most naturalistic method of obtaining a sample of the children's connected speech and led to complementary results to that of the sentence task. A strength of the speech sample was the substantial information that could be gained about a child's speech sound inventory if the child was very outgoing. Daniel was this participant, who demonstrated excitement for the chance to share about his experiences and insights about a particular topic. Eagerness in children may be an effective way to obtain a speech sample because they want to engage in conversation. Because of this, Daniel provided a very rich speech sample to analyze, which included information provided about his speech sound inventory, PCC, and phonological error patterns. These pieces of information revealed many speech sounds he was producing in spontaneous speech and if those sounds were being produced accurately or in error.

On the other hand, a weakness of the speech sample as an assessment was trying to obtain phrases and words needed to analyze a sample and the method of elicitation, which incorporated the Mercer Mayer wordless books. For two of the three participants, Micah and Eli, engaging them in conversation via the wordless books or even through topics of interest when that failed (e.g. "What is your favorite book about?" or "Tell me about your favorite toys") was difficult because they may have been tired from completing the other assessments or too shy. The speech samples also may have been difficult for a couple of the participants because rather than labeling pictures or imitating the examiner, they are the ones who have to generate their own words and phrases 
(DuBois \& Bernthal, 1978). Micah's mother, who was present during testing, mentioned that it might have been hard to obtain a speech sample from Micah because it might have been too hard for him to generate the language to narrate the book. The examiner tried to facilitate speech production by asking questions about the book he chose (e.g. "Where is the boy going?" or "Why is the boy sad?"), but Micah kept getting up from the table, saying he was done and telling the examiner that he did not have to say anything about the book.

Eli's speech sample required the greatest examiner effort to obtain out of all the participants because he was unwilling to narrate a wordless book or engage in conversation with the examiner. Narrating a book may have been especially difficult for Eli because not only did he have to generate his own words, but he also had a mild language impairment. This may have decreased the amount of language he was able to produce in his speech sample, and in turn, limited his attempt at various speech sounds.

A weakness of the speech sample is the difficulty of determining if lack of speech sounds is indicative of a child's overall speech system or results from limitations of the words targeted in the sample. This was seen in the limited number of speech sounds targeted in Eli's speech sample. Even if a complete speech sample had been obtained from him, his speech sound inventory may not have changed very much because there were more speech sounds not produced in his speech sample when compared to his word and sentence task. Daniel and Micah's phonetic inventory of all three assessments reiterates this point because there were fewer speech sounds produced in their speech sample when compared to their word and sentence task, and they both had a complete speech sample to analyze. 
Despite the challenges with Micah and Eli, the method of using the Mercer Mayer wordless books was successful with Daniel because he was interested in each picture and the story it was telling. This method of elicitation is often used to elicit a spontaneous speech sample (Hodson et al., 2002; Miccio, 2002) because it allows the clinician to successfully obtain a sample and can lead to open-ended questions to elicit additional speech from a child.

\section{Single-Word Task}

While the sentence task and speech sample captured what each participant was producing in their connected speech, with and without imitation, the single-word task provided information about their abilities at the word level.

A strength of the word task is the increased number of opportunities for production of speech sounds when compared to the sentence task or speech sample. The word task showed 2 out of 3 participants producing the second highest number of variety of speech sounds, next to the sentence task.

Weaknesses of the word task were the length of time needed to administer the assessment, the high number of words in the task, and the time needed to transcribe the sample. The longer administration and transcription time may be attributed to examiner effort because of the limited exposure with the PABA-E and LIPP transcription. Although this may be true, speech assessments that are typically used for speech testing, such as the GFTA-2 (Goldman \& Fristoe, 2000), the PAT-3 (Pendergast, Dickey, Selmar, \& Soder, 1997), and the HAPP-3 (Hodson, 2004), contain a smaller amount of target words, ranging from 53 to just over 70 words. All of these assessments have been designed to take less than 20 minutes to administer. 
The high number of words in the task may have been difficult for Eli to complete; therefore, increasing his completion time. When the examiner prompted him with, "This is a _," Eli responded, "I don't know" about one-third of the time. It is possible that this may have been due to his mild language impairment, and one of his challenges may have been labeling nouns. Another possibility may be that his attention and engagement with the examiner was lower because he was focusing more on the game that the examiner associated with the word task. The examiner tried to use a motivating game to increase speech production, which involved feeding animals a piece of food each time he said a word during the word task.

While the Micah and Eli may have viewed this task as a chore, Daniel appeared to enjoy the word task. He named each picture quickly with almost no assistance from the examiner. He enjoyed seeing a picture and telling the examiner what he knew about that particular object or action.

In terms of errors in the participants' speech, the percent occurrence of error patterns was neither the highest or lowest percentage for participants in their word task. For PCC, the majority of participants had a lower PCC when looking across all speech assessments and for medial word position, which means they were producing consonants at a lower accuracy rate when compared to running speech. This may have occurred because children generally do not produce words in their spontaneous speech that are too difficult for them to produce (DuBois \& Bernthal, 1978); in contrast, in the word tasks there may have been words that were difficult for the participants to produce.

\section{Time of Elicitation}

The time needed to administer each assessment is an important consideration 
when selecting assessment instruments. The high volume of words in the word task may be too many for the limited amount of time it takes for an SLP to complete an assessment. Even Daniel, who was able to complete that particular task with almost no hesitations or prompting, took just over 17 minutes to complete, while the other participants took over 22 minutes to complete the task. A single assessment that targets over 130 words seemed to be exhausting for almost all of the participants, although the longer administration time could be due to the examiner's limited exposure to administering a speech assessment of this length. That being said, most single-word articulation assessments available have a shorter administration time and are usually transcribed online. For the purposes of this study, online transcription was not used in order to keep each participant engaged to complete each assessment.

Another reason why Micah's and Eli's time elicitation for the word task took longer than Daniel's was due to small breaks Micah needed to take after each set of 20 or 30 words and Eli's lack of focus, which resulted in longer pauses between words. Even though Daniel's elicitation time was the lowest of all the participants, it could have been even lower had he not chatted in between many of the pictures.

The amount of time it took for each participant to complete the sentence task was very short in comparison to the word task, which was less than half the time. It took Micah and Eli about twice as long as Daniel to complete the task because on many sentences, they both needed more than prompt to imitate the examiner and in Micah's case, he took a few breaks (i.e., got up from the table a few times).

The speech samples may have been may have been one of the more difficult assessments to obtain, but for two of the three participants, they were fairly representative 
of the participant's speech sound inventory. The exception would be Eli's speech sample due to the increased number of speech sounds not attempted as compared to the other two participants.

\section{Phonological Error Patterns}

Six phonological error patterns were analyzed within the participants' assessments and results were varied. Since Eli's speech sample was not complete, the analysis of his phonological error patterns in his speech sample was recorded, but not included as part of the following discussion with the other participants because his percentages may not be a valid representation of his spontaneous speech.

The information gained from analyzing Daniel and Micah's phonological error patterns did not give a clear indicator that they always produced a higher or lower percentage of error patterns on one assessment over another. When looking across these results, each of the assessments had a different percentage of error patterns. Micah's speech sample had a higher percentage of phonological errors out of all his assessments, although higher is relative because two of the four error patterns that showed a higher percentage in his speech sample were all under $10 \%$. Daniel produced a higher number of phonological error patterns in his sentence task.

In comparing Eli's word and sentence task, all percentages were within $1 \%$ to $10 \%$ of each other, and neither of those assessments consistently gave a higher percentage of error patterns. For comparison of the lowest percentages of error patterns, no assessment, for any participant, had a consistent lower percentage of phonological error patterns than another. This is similar to the results of past research in that comparing single-word tasks to spontaneous speech samples does not always show one 
type of assessment as containing higher or lower percentages of error patterns, but rather certain patterns are more likely to show up in one assessment over another (Healy \& Madison, 1987; Klein, 1984; Johnson et al., 1980).

\section{Percent Consonants Correct}

PCC was examined for all three of Daniel and Micah's assessments and Eli's PABA-E tasks to look at how accurately each of them were producing consonants in various contexts. Daniel and Micah's PCC for each assessment should be a fair representation of their overall PCC because they had a complete speech sample to analyze.

A higher percentage for overall PCC was found in 2 of the 3 participants' sentence task. The word task was the assessment that yielded the lowest PCC for two of the three participants, which could be contributed to an increased number of words targeted in the word task that may have been too difficult for one or more of the participants to produce (DuBois \& Bernthal, 1978).

When PCC was calculated by word position, it was higher for 2 of 3 participants in initial word position for the speech sample and in medial and final word position for the word task. The sentence task had the lowest PCC for all three word positions for 2 out of 3 participants.

There was discrepancy between the PCC values for Eli's speech sample compared to his word and sentence task. His word and sentence task percentages for overall PCC and by word position were consistently within less than $1 \%$ to $5 \%$ of each other. On the other hand, his short speech sample percentages were within $7 \%$ to $22 \%$ of the next highest or lowest assessment PCC, which is higher than the gap between percentages of 
assessments completed.

\section{Speech Transcription}

The amount of time for transcription into LIPP was different for each participant, depending on the assessment being transcribed. One potential reason for the time difference from one participant to the next is the limited amount of experience the researcher had using LIPP, prior to this study. As the researcher gained more experience using LIPP, the amount of time needed for transcription decreased. Although the word task took more time to transcribe, the speech sample was the most difficult to transcribe because there was no template for the speech sample of a participant. This added to the time needed to identify the adult target, enter it into LIPP, and then enter the phonetic transcription of the target.

The PABA-E had templates already established for the word and sentence task in LIPP, which contributed to the relative ease of phonetically transcribing each assessment. Although templates existed, the word task still took a longer period of time to transcribe because of the increased number of words within the assessment. In Eli's case, even though his assessments were the last ones to be entered into LIPP, his word and sentence task took a longer time to transcribe because his voice was quiet, the recording needed to be listened to multiple times, and due to his need for each sentences in the sentence task to be administered one to two words at a time, and also repeated more than one time.

An increased length of time needed to transcribe each assessment could also be due to transcription being completed after testing, rather than transcribing online. Typically, when a standardized assessment is given to a child, the clinician attempts to transcribe online, which would decrease the amount of time needed to go back and 
transcribe after the assessment was over.

\section{Clinical Implications}

For clients with concerns of language impairments, obtaining a speech sample may not be the most effective or efficient method when trying to gain more information about the child's speech sound inventory. The speech sample would most likely take a longer period of time to obtain because the child may be producing less speech at a slower rate, compared to children with no language impairments. Despite these results, using only one of the assessments in this study may not give the most comprehensive data on a child's speech production abilities. Obtaining a clear picture of the speech production abilities of children is important because it can help to guide treatment and provide a baseline when assessing their progress during treatment.

Using more than one assessment, most likely a standardized and non standardized assessment, has been the most widely recommended protocol for conducting a speech assessment; however, this recommendation is not always observed in clinical practice (Hodson et al, 2002; Hoffman \& Norris, 2002; Khan, 2002; Miccio, 2002; Tyler \& Tolbert, 2002;). For many clinicians, obtaining and analyzing a speech sample is not always a reality, especially in a school setting for an SLP because of time constraints. Using a standardized assessment such as the Goldman Fristoe-2 or the PAT-3 is usually used to gain information about a child's speech sound inventory. A connected speech sample is also obtained from a child, but is most likely used for a language sample, with a small amount of data taken on speech sounds produced that were not produced on the standardized test. In this case, using a delayed sentence imitation task, like the one in the PABA-E, would likely be the assessment that would give a clinician the most 
comprehensive information about a child's phonetic inventory by employing the use of a standardized method, but also bringing in the aspect of a child's connected speech. Using the imitated sentence task would also provide information about PCC and error patterns for children suspected of having a speech sound disorder.

\section{Limitations}

The largest limitation of this study was the limited number of participations. It is impossible to extrapolate findings from three individuals who varied widely in responses to all children with speech sound disorders. While the findings from the current study are interesting and useful to future researchers, the result of this study of three children cannot be assumed to be representative of all children.

Bringing toys and games into the testing room with Eli was a challenging way to complete the assessment. Although this appeared to motivate him to be in the room because he was very shy and nervous, this may have been too distracting for him to focus on the assessments. Children may experience shyness or nervousness when dealing with assessment situations, and it can be a factor in a client not wanting to be in the room for an assessment or wanting to complete any part of an assessment. Clinicians would need to use their own judgment when deciding on how to motivate a child to complete an assessment, if that is necessary.

The use of the wordless books to generate a speech sample may have been challenging for a couple of the participants because of the language aspect of narrating a book. For children who are not interested in looking through books, especially ones without words, this method of obtaining a speech sample may not be motivating enough for them to engage in conversation with the examiner. 
It is important to consider the effect of testing environment on results. In the current study, two participants, Daniel and Micah, completed testing in their home, a seemingly comfortable environment to them. Eli was in a clinic room, which may have been familiar to him, since it was the room he does therapy in, but may not have been a comfortable environment for him to complete testing.

\section{Conclusions}

One of the main purposes of this study was to find out if results of the PABA-E would be similar to that of a spontaneous speech sample regarding speech production ability in children. The results showed that while overall there were large similarities between children, each child's speech production ability varied in each assessment given, meaning that each assessment provided different kinds of information about each participants' speech production abilities. Although research has shown that connected speech is a more likely representation of children's speech and their speech sound errors (DuBois \& Bernthal, 1978; Faircloth \& Faircloth, 1970; Healy \& Madison, 1987; Klein, 1984; Morrison \& Shriberg, 1992), the imitated sentence task from this study was shown to provide a bigger picture of the speech sounds children produce over the spontaneous speech sample. In fact, the participants' produced the next largest variety of speech sounds in their single-word task because their speech samples did not target all the speech sounds that were targeted in the other two assessments. Aside from the participants' phonetic inventories, the percentages of phonological error patterns were found to be higher in the single-word and imitated sentence task, depending on the participants' data. Lower percentages of error patterns could be found in the sentence task and speech samples. Overall PCC results showed a higher PCC for the sentence task (if Eli's speech 
sample is not taken into account), but the single-word task generally had a lower PCC.

In terms of effectiveness and efficiency of the three assessments, the imitated sentence task not only took the least amount of time to administer, but also appeared to provide the most comprehensive information about each participant's speech sound inventory. The speech sample was helpful in providing information regarding speech sound inventory, but was limited to the sounds that were attempted by the participants. This does not discount the use of a single-word task because additional information about speech sound production was gained through the task, but rather highlights the greater benefit of using the imitated sentence task.

Transcription time was also a factor in this study because it added to the results of how efficient each assessment could be. The PABA-E, in particular the sentence task, was shown to take the least amount of time to transcribe. This adds to the efficiency of a shorter administration time. Having access to LIPP or another phonetic transcription software program would be important when thinking about transcribing the assessments in the PABA-E since templates for the assessments already exist and LIPP has the ability to analyze the transcription.

\section{Future research}

This study showed the benefits of administering an imitated sentence task to gain information about a child's speech sound inventory with a speech sound disorder. A study conducted with a larger number of children with speech sound disorders should be done in order for statistics to be reported, including data on the production of word complexity for each participant. This would provide more data about the use of an imitated sentence task and how the assessment results compare to the single-word task 
and a spontaneous speech sample. Conducting this study with female participants with a SSD could also be done, as this study had only male participants. As more research is conducted on the PABA-E and the potential benefits of using an imitated sentence task during a speech assessment, standardization of the PABA-E would be the next step, in order to show how children compare to same-age peers in terms of speech development. 


\section{References}

American Speech-Language-Hearing Association. (1997-2009). Speech Sound Disorders: Articulation and Phonological Processes. Retrieved from http://www.asha.org/public/speech/disorders/SpeechSoundDisorders.htm

Andrews, N., \& Fey, M. (1986). Analysis of the speech of phonologically impaired children in two sampling conditions. Language, Speech, and Hearing Services in Schools, 17, 187-198.

Bankson, N. \& Bernthal. J. (1990). Bankson-Bernthal Test of Phonology. PRO-ED.

Bleile, K. (2002). Evaluating articulation and phonological disorders when the clock is running. American Journal of Speech-Language Pathology, 11, 243- 249.

DuBois, E., \& Bernthal, J. (1978). A comparison of three methods for obtaining articulatory responses. Journal of Speech and Hearing Disorders, 43, 295-305

Dyson, A., \& Robinson, T. (1987). The effect of phonological analysis procedure on the selection of potential remediation targets. Language, Speech, and Hearing Services in Schools, 18, 364-377.

Faircloth, M., \& Faircloth, S. (1970). An analysis of the articulator behavior of a speechdefective child in connected speech and in isolated-word responses. Journal of Speech and Hearing Disorders, 35, 51-61.

Fey, M. (1992). Articulation and phonology: Inextricable constructs in speech pathology. Language, Speech, and Hearing Services in Schools, 23, 25-232.

Gildersleeve-Neumann, C. (2008). Phonological and Articulatory Bilingual Assessment English. Unpublished. 
Goldman, R. \& Fristoe, M. (2000). Goldman Fristoe Test of Articulation-2. AGS Publishing/Pearson Assessments.

Gordon-Brannan, M., \& Weiss, C. (2007). Clinical management of articulatory and phonological disorders $\left(3^{\text {rd }}\right.$. ed.). Baltimore, MD: Lippincott Williams \& Wilkins.

Hale-Haniff, M. \& Siegel, G.M., (1981). The effect on context on verbal elicited imitation. Journal of Speech and Hearing Disorders, 46: 27-30.

Haynes, W., \& Steed, S. (1987). Multiphonemic scoring of articulation in imitative sentences: Some preliminary data. Language, Speech, and Hearing Services in Schools, 18, 4-14.

Healy, T., \& Madison, C. (1987). Articulation error migration: A comparison of single words and connected speech samples. Journal of Communication Disorders, 20, 129136.

Hodson, B.W. (2004). Hodson Assessment of Phonological Patterns - 3. PRO-ED.

Hodson, B., Scherz, J., \& Strattman, K. (2002). Evaluating communicative abilities of a highly unintelligible pre-schooler. American Journal of Speech-Language Pathology, $11,236-242$.

Hoffman, P., \& Norris, J. (2002). Phonological assessment as an integral part of language assessment. American Journal of Speech-Language Pathology, 11, 230-235.

Ingram, D. (1994). Articulation testing versus conversational speech sampling: A response to Morrison and Shriberg (1992). Journal of Speech and Hearing Research, $37,935$.

Johnson, J., Winney, B., \& Pederson, O. (1980). Single words versus connected speech articulation testing. Language, Speech \& Hearing Services in Schools, 11, 175-179. 
Kent, R., Miolo, G., \& Bloedel, S. (1994). The intelligibility of children's speech: A review of evaluation procedures. American Journal of Speech-Language Pathology, 3, 81-95.

Khan, L. (2002). The sixth view: Assessing preschool children's articulation and phonology from the trenches. American Journal of Speech-Language Pathology, 11, 250-254.

Klein, H. (1984). Procedure for maximizing phonological information from single-word responses. Language, Speech, and Hearing Services in Schools, 15, 267-274.

Klein, H.B. \& Liu-Shea. M. (2009). Between-word simplification patterns in the continuous speech of children with speech sound disorders. Language, Speech, \& Hearing Services in Schools, 40, 17-30.

Masterson, J \& Bernhardt, B. (2001). Computerized Articulation and Phonology Evaluation System. Hardcourt Assessment.

Masterson, J., Bernhardt, B., \& Hofheinz, M. (2005). A comparison of single words and conversational speech in phonological evaluation. American Journal of SpeechLanguage Pathology, 14, 229-241.

Mayer, Mercer. (1967). A boy, a dog, and a frog. NY: Dial Books for Young Readers. Mayer, Mercer. (1974). Frog goes to dinner. NY: Penguin Group.

Mayer, Mercer. (1975). One frog too many. NY: Dial Books for Young Readers.

Miccio, A. (2002). Clinical problem solving: Assessment of phonological disorders. American Journal of Speech-Language Pathology, 11, 221-229.

Morris, S.R., Wilcox, K.A., \& Schooling, T.L. (1995). The preschool speech intelligibility measure. American Journal of Speech-Language Pathology, 4, 22-28. 
Morrison, J. \& Shriberg, L. (1992). Articulation testing versus conversational speech sampling. Journal of Speech and Hearing Research, 35, 259-273.

Oller \& Delgado. (2000). Logical International Phonetic Program (LIPP) (Version 2.02). Miami, FL: Intelligent Hearing Systems.

Paden, E. \& Moss, S. (1985). Comparison of three phonological analysis procedures. Language, Speech, and Hearing Services in Schools, 16, 103-109.

Paynter, E., \& Bumpas, T. (1977). Imitative and spontaneous articulatory assessment of three-year-old children. Journal of speech and Hearing disorders, 17, 119-125.

Pendergast, K., Dickey, S., Selmar, J., \& Soder, A. (1997). Photo articulation test - 3. PRO-ED.

Shriberg, L., Austin, D., Lewis, B., McSweeny, J., \& Wilson, D. (1997). The percentage of consonants correct (PCC) metric: Extensions and reliability data. Journal of Speech, Language, and Hearing Research, 40, 708-722.

Shriberg, L., \& Kwiatkowski, J. (1980). Natural processes analysis: A procedure for phonological analysis of continuous speech samples. New York: Macmillan.

Siegel, R., Winitz, H., \& Conkey, H. (1963). The influence of testing instruments on articulatory responses in children. Journal of Speech and Hearing Disorders, 28, 6776.

Smith, M., \& Ainsworth, S. (1967). The effects of three types of stimulation on articulatory responses of speech defective children. Journal of Speech and Hearing Research, 10, 333-338.

Tyler, A., \& Tolbert, L. (2002). Speech-language assessment in the clinical setting. American Journal of Speech-Language Pathology, 11, 215-220. 
Wolk, L., \& Meisler, A. (1998). Phonological assessment: A systematic comparison of conversation naming and picture naming. Journal of Communication Disorders, 31, 291-313. 


\section{Appendix A: Parent Questionnaire of Child's Speech Development}

\section{Participant \#}

\section{Child's Name:}

Your Name:

Your Relationship to Child:

Date of Birth:

Date of Testing:

Age:

Person Completing Survey:

Section 1. DEVELOPMENT HISTORY. These questions help us understand your child's development. If you have questions or concerns about a question, please feel free to not answer or to ask for clarification.

\section{Family History:}

\begin{tabular}{|c|l|l|l|l|}
\hline & Name & Age & Occupation & Education Level \\
\hline Mother & & & & \\
\hline Father & & & & \\
\hline $\begin{array}{c}\text { Sisters/ } \\
\text { Brothers }\end{array}$ & & & & \\
\hline & & & & \\
\hline
\end{tabular}

1. Where was your child born?

2. Where were the child's parents born?

3. What language(s) do the child's parents and child speak?

4. Is your child's first language English?

5. How old was your child when he or she first babbled (e.g., say bababa or dadada)?

6. How old was your child when he or she first spoke three different words? What were they?

7. How old was your child when he or she started saying 2 and 3 word sentences on a regular basis?

8. How old was your child when she or he first spoke in sentences, even though some of the words in the sentence may have been missing?

9. Has your child ever had his or her hearing checked? What were the results?

10. Has your child ever been tested for a language disorder? If so, what test was given and what were the results?

11. What schools has your child attended?

12. Has your child been treated for ear infections? If yes, how many times? When were they?

13. Has your child ever had a serious illness or been hospitalized? If yes, please explain.

14. Does your child have any diagnosed medical conditions? If so, please explain.

15. Do you have any concerns about your child's general development? If so, what are they? 


\section{Appendix B: Informed Consent}

A Comparison of Single Word Identification, Connected Speech Samples, and Imitated Sentence Tasks for Assessment of Children with SSD

To the Parents of (Prospective Child):

My name is Emily Snyder, and I am a Speech and Hearing Sciences graduate student at Portland State University. To complete requirements for a master's thesis at PSU, I am beginning a study on assessments of children with a speech sound disorder and would like to invite your child to participate. My study will compare single-word, imitated sentence and conversational speech samples as assessment tools to determine whether one type of testing instrument is more efficiently and/or effective when assessing children who have a speech sound disorder. I am conducting this study under the supervision of Christina Gildersleeve-Neumann, Ph.D., a professor at PSU and certified speech-language pathologist.

You are being asked to take part because your child was referred for or has a speech sound disorder. During this study, I hope that the information I collect will help us to better understand the information gleaned from assessments of speech sound disorders. If you decide to allow your child to participate, you will be asked to fill out a questionnaire about your child's speech and language development and also let your child participate in a few assessments for a speech sound disorder. It should take approximately 10-20 minutes to complete the questionnaire and anywhere from $45-80$ minutes to complete the assessments, which will audio recorded and videotaped. The questionnaire can be filled out on your own time and the assessment will take place on a different day that is convenient for you and your family.

As a result of this study, you may have to take no more than 1 and half hours out of your schedule to allow for completion of assessments and it is possible that your child may experience slight boredom or mild frustration with the assessments. However, I assure you that the assessment will be completed as quickly as possible so as to not cause you or your family any inconvenience. These assessment instruments are not longer or more difficult than assessments that your child would have during a non-research speech assessment.

You and your child may benefit directly from this study by providing you information about your child if your child has been referred for a speech sound disorder. You may also benefit indirectly from participating because this study may help to increase knowledge about assessment of speech sound disorder that may help others in the future.

Any information that is obtained in connection with this study and that can be linked to you or identify you will be kept confidential. Subject identities will be kept confidential 
by only using participants' initials throughout the study and keeping all records, including video and audio recordings, locked up in Dr. Gildersleeve-Neumann's speech lab in Portland State University's Neuberger Hall, Room 69.

Participation is entirely voluntary. Your decision to participate or not will not affect your relationship with the researcher or with your child's preschool in any way. If you decide to take part in the study, you may choose to withdraw at any time without penalty. I will give you a copy of this letter for your records. If you have concerns or problems about your participation in this study or your rights as a research subject, please contact the Human Subjects Research Review Committee, Office of Research and Sponsored Projects, 600 Unitus Bldg., Portland State University, (503) 725-4288 / 1-877-480-4400.

If you have questions about the study itself, contact Emily Snyder at (503) 805-3632.

Sincerely, Emily Snyder, Graduate Student Clinician

Portland State University

I , agree to let my child

participate in the study and agree to the procedures of the assessment mentioned above.

Signature

Date

Print 
Appendix C: PABA-E

\section{Single-Word List (138 words)}

$\begin{array}{llllll}\text { apples } & \text { chair } & \text { fork } & \text { lamp } & \text { red } & \text { string } \\ \text { baby } & \text { chicken } & \text { four } & \text { leaf } & \text { ring } & \text { swinging } \\ \text { balls } & \text { chocolate } & \text { french fries } & \text { lips } & \text { school } & \text { teacher } \\ \text { banana } & \text { clouds } & \text { frog } & \text { little } & \text { scissors } & \text { teeth } \\ \text { bath } & \text { cookies } & \text { gate } & \text { milk } & \text { seven } & \text { ten } \\ \text { bathtub } & \text { cup } & \text { giraffe } & \text { mirror } & \text { sheep } & \text { this/that } \\ \text { big } & \text { dinosaur } & \text { girl } & \text { mountains } & \text { ship } & \text { three } \\ \text { bike } & \text { dog } & \text { glasses } & \text { mouse } & \text { sick } & \text { throwing } \\ \text { bird } & \text { door } & \text { goose } & \text { mouth } & \text { six } & \text { tiger } \\ \text { black } & \text { drinking } & \text { grapes } & \text { nest } & \text { skates } & \text { toe } \\ \text { boat } & \text { drum } & \text { guitar } & \text { nine } & \text { slide } & \text { tongue } \\ \text { books } & \text { eggs } & \text { hamburger } & \text { one } & \text { smile } & \text { toothpaste } \\ \text { boot } & \text { eight } & \text { hammer } & \text { orange } & \text { smoke } & \text { toys } \\ \text { boy } & \text { elephant } & \text { hand } & \text { pancakes } & \text { snake } & \text { truck } \\ \text { brother } & \text { face } & \text { helicopter } & \text { pants } & \text { soap } & \text { two } \\ \text { brush } & \text { feather } & \text { horse } & \text { pencil } & \text { sock } & \text { vacuum } \\ \text { butterfly } & \text { feet } & \text { house } & \text { pet } & \text { soup } & \text { watch } \\ \text { cake } & \text { finger } & \text { ice cream } & \text { pie } & \text { spider } & \text { waterfall } \\ \text { candle } & \text { fire truck } & \text { jacket } & \text { pig } & \text { spoon } & \text { yellow } \\ \text { carrots } & \text { fish } & \text { jet } & \text { planes } & \text { squirrel } & \text { zipper } \\ \text { cars } & \text { five } & \text { juice } & \text { pool } & \text { stars } & \\ \text { cat } & \text { flower } & \text { jumping } & \text { puppy } & \text { stop } & \\ \text { caterpillar } & \text { foot } & \text { kitchen } & \text { rainbow } & \text { strawberry } & \end{array}$

\section{Imitated Sentences List}

1. The yellow duck is swimming fast.

2. A big frog jumped over the bathtub.

3. I love milk and cookies.

4. Our younger brother has a broken foot.

5. Spotted elephants like green bananas.

6. There are five candles on my birthday cake.

7. I read a small book about a dinosaur.

8. Three sheep played in the flowers.

9. She's trying to cut paper with good scissors.

10. The toy firetruck drove over the mountains.

11. The chicken laid an orange egg outside.

12. We eat yogurt through a straw.

13. She brushed her teeth with chocolate toothpaste.

14. The young girl likes blueberry jam.

15. Her school teacher is wearing noisy shoes.

16. The boy's jacket looks warm.

17. Six rabbits hopped across the street.

18. Seven kids are making peanut butter and jelly sandwiches. 